\title{
Integrating Novel Methods and Existing Tools to Enrich Nontraditional Learn- ing Experiences
}

\section{Mrs. Shannon Banner, North Carolina State University}

Mrs. Banner is a research assistant and is currently pursuing her PhD in Biological and Agricultural Engineering from North Carolina State University. Her research is focused on modeling environmental impact and economic feasibility of technology systems applied to animal waste management. She is a member of ASABE and SWE. Address: Weaver Laboratories, Campus Box 7625, Raleigh, NC 27695 Phone: 336-577-3757

\section{Dr. John J. Classen, North Carolina State University}

Associate Professor and Director of Graduate Programs, Biological and Agricultural Engineering, North Carolina State University. Professional interests focus on nutrient and value recovery from food animal production systems, food security, and graduate education. 


\title{
Integrating Novel Methods and Existing Tools to Enrich Non-traditional Learning Experiences
}

\begin{abstract}
The methodology described in this working paper is a module designed to teach the concepts of environmental and economic analysis which are then reinforced through a decision-making game applied to resource recovery in animal agriculture. In this digital age information transfer is increasingly being carried out through non-traditional outlets and open source platforms (i.e. Moodle and Sakai) which provide new opportunities to enhance and complement hands-on learning. In 2018 the concept of virtual learning is well established but the application of games and game-design elements as a part of learning is still a largely underutilized tool in most sectors. Incorporating new ways to disseminate information with well-established existing methods provides a potentially more effective platform for teaching complex topics. In addition, these methods help to build versatile communication skills that can be widely applied to different industries, environments, problems, and users.

The initial version of the module was developed in Moodle 3.2 and implemented in a graduate level distance learning animal waste management class at North Carolina State University. The first part of the module was created using the Moodle book activity and included short chapters in which topic-specific information was presented using multiple types of media (text, presentations, videos, and references). The second part of the module incorporated a novel game element where the students took on the role of a consultant tasked with helping a farmer make decisions about implementing different technologies to manage on-farm waste and nutrients. The effectiveness of the module and the learning techniques were evaluated through the use of pre and post surveys as well as graded quizzes. Survey feedback from pre and post surveys indicated that there was an overall increase in the students' familiarity and understanding of terminology and concepts after completion of the module. While the initial version was designed to be completed within a two-week timeframe, future development will include a second and more refined version based on feedback received from participant surveys that could in time produce a generic and adaptable stand-alone tool used for information transfer applied to variable topic areas and stakeholders.
\end{abstract}

\section{Introduction}

Instructors recognize that key components of traditional face-to-face learning such as engagement, communication, and feedback must also be incorporated in a distance learning (DL) setting for effective delivery, comprehension, and retention of information [1]. With new tools and resources being released on what seems an almost daily basis, instructors are faced with the challenges of knowing what's out there and if/how they can integrate it into their existing courses. One could argue this is particularly true in DL environments. The application of games and game-design elements is still relatively new in most sectors, including academia, but incorporating new ways to disseminate information with well-established existing methods provides a potentially more effective platform for teaching complex topics. In addition, these methods can help to build versatile skillsets that can be widely applied to different industries, environments, problems, and users. The module described in this paper was applied in an existing graduate level DL course on animal waste management. The course already included concepts related to waste management and nutrient recovery technology design so the purpose of the module was to introduce additional concepts that applied technology evaluation based on 
environmental and economic assessment. Students' understanding of the concepts was reinforced through a decision-making game applied to resource recovery in animal agriculture.

\section{Background}

A distinction should be made between games and gamification. There are numerous definitions of gamification but in this paper we define gamification as "the process of incorporating games and/or game mechanics to digitally engage and motivate user participation and enhance user experience” ([2], [3]). Based on this definition, gamification elements including objectives, points, progress, and feedback were used in the initial version of the module. Gamification has gained popularity in the last 10-15 years due to advancements in both computer technology and recognition of its usefulness as a tool for providing the key concepts of feedback, communication, and engagement mentioned previously. In DL courses it can also provide the additional elements of decision-making and problem-solving applied to real-world scenarios. In academia gamification has been used in a variety of engineering disciplines including engineering design, industrial engineering, electrical engineering, and computer engineering ([4] - [8]) ). At North Carolina State University, there has been very limited use of gamification in either DL or traditional classes and none in agricultural engineering. Many of the same skills and needs related to real-world problem solving exist across disciplines and gamification provides a potential bridge between DL and traditional learning when it comes to teaching complex topics.

\section{Methods}

\section{Students and Course Structure}

The module was used in an existing graduate course in Biological and Agricultural Engineering at North Carolina State University, Agricultural Waste Management. Students with varying interests and backgrounds are encouraged to enroll but prerequisites limit enrollment to graduate and undergraduate students from agricultural or life sciences and engineering. This is an introductory class in that a prior course on this topic is not required but the instructor's expectations of in-depth analysis, independent investigation, advanced writing skills, online teamwork, and critical thinking make this a graduate level course.

\section{Student Objective and Activities}

Students were given one week each to complete the self-paced first and second parts of the module. During the two weeks students gained data modeling skills through the use of module part 1 activities which were then applied to complete the module part 2 activity, a decisionmaking game related to animal production and resource recovery. In alignment with the purpose of the study, students were presented with the following objectives at the introduction of the module:

1) Describe selected technologies, their benefits, and their limitations for application to manure management

2) Identify the strengths and limitations of environmental and economic models

3) Apply selected models used for environmental and economic assessment to agriculture and animal production

4) Demonstrate knowledge of material through a role-playing game 
Student competency for objectives 1 and 2 were evaluated using graded quizzes while competency for objectives 3 and 4 were evaluated by successful completion of the role-playing game and comparison of pre and post survey feedback. Based on the revised version of Bloom's Taxonomy of Educational Objectives [9] the two parts of the module served very different functions. The first part of the module (book activity) had a higher emphasis on remembering and understanding the information presented while the second part of the module (decisionmaking game) was specifically designed to simulate real-world scenarios and required the students to apply, analyze, and self-evaluate decisions made by building on the information presented in the first part of the module.

\section{Module components}

\section{Moodle}

The initial version of the module was developed in Moodle 3.2 and implemented in a graduate level distance learning animal waste management class at North Carolina State University. The first part of the module was created using the Moodle book activity which included short chapters in which topic-specific information was presented using multiple types of media (text, presentations, videos, and references). The second part of the module incorporated a novel game element where the student acted as a consultant and given the task of helping a farmer make decisions about changes to their farm related to implementing potential waste and nutrient management technologies.

\section{Book}

Several advantages of using the Moodle book activity (Fig. 1) to present information were that students could easily navigate the entire activity content through a table of contents, students could print individual chapters or the entire book activity for further reference, and key terms within the pages could be linked to a glossary activity which allowed them to hover over a term while still remaining on the page to get definitions of concepts (Fig. 2). The book activity was a new addition to the current course and was separated into two main sections environmental assessment and economic assessment - within each of these parts a brief overview was given of various modeling methods. For the environmental section the presented subcategories were decision support tools (DST's), environmental impact assessment (EIA), strategic environmental assessment (SEA), and environmental life cycle assessment (LCA). For the economic

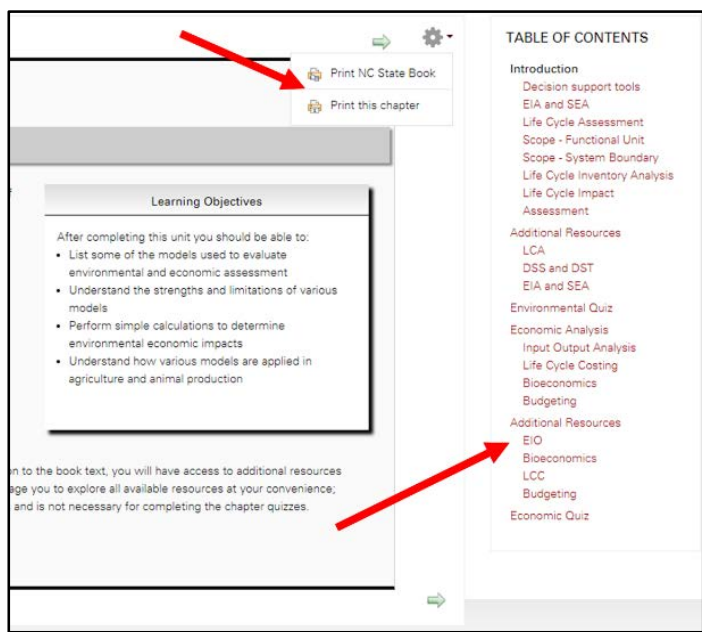

Fig. 1: Moodle book activity features section the subcategories presented were input output analysis (IO), life cycle costing (LCC), bioeconomics, and budgeting. To facilitate the two week timeframe each subcategory was, when possible, limited to one book page. The exceptions were environmental life cycle assessment (LCA) and partial budgeting as in-depth understanding of these topics would specifically be needed to complete the decision-making game in part 2 of the module. 


\section{Glossary}

The glossary activity in Moodle is helpful in that it allows the instructor to provide more in depth information (references, videos, and links) without taking up additional space on the main book page. Additionally the glossary settings allow the instructor to toggle linking "on and off" for specific activities which means that they can turn on linking to the book content and turn it off for the graded quizzes.

\section{Additional resources}

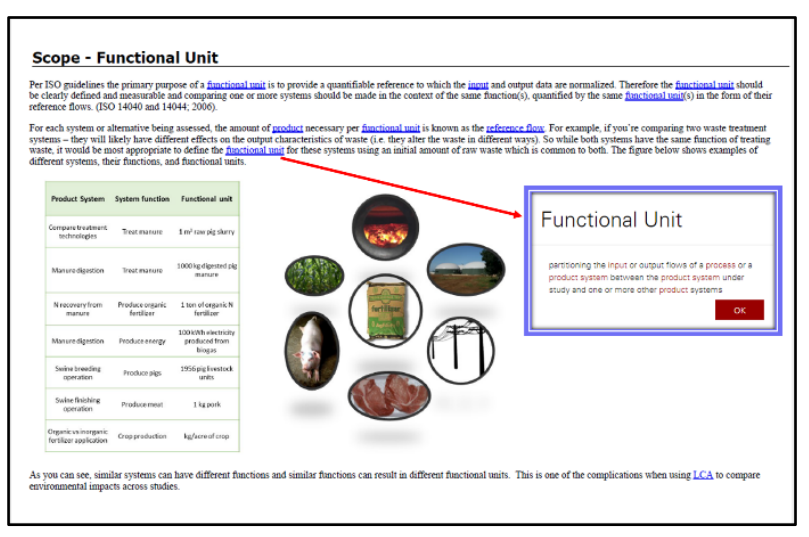

Fig. 2: Glossary used in Moodle book page

Narrated Microsoft PowerPoint ${ }^{\circledR}$ presentations were used to provide additional depth to the topics of integrated modeling and sustainability applied to agriculture and environmental life cycle assessment (LCA) which were considered important for a broader perspective of the course content but could not be fully addressed in a two-week time period. The presentations were entitled "The Intersection of Economics, Environment, and Society" and "Life Cycle Assessment" respectively. In the interest of time and to make sure the students had a more indepth understanding of the briefly discussed topics additional (non-mandatory) resources in the form of videos, journal articles, and web pages were also provided.

\section{Game Design}

In decision-making games each choice may result in numerous outcomes, which in turn leads to additional choices and yet more outcomes. While creating the game it quickly became apparent that even a fixed set of outcomes resulted in a very complex structure. Given the text-based structure of the Moodle lesson activity which was ultimately used to create the game, a decision tree (Fig. 3) was first generated to visualize graphically all possible choices and outcomes. After the decision tree was complete the information was manually entered into the Moodle lesson which functions similarly to the Moodle book. Two advantages of using the lesson over the book for this particular application are that each page can be linked to another page and quiz-like questions that award points can be included as content within the pages. The students were informed prior to beginning the game that they would be asked a series of questions varying from simple yes or no responses to those that required calculations and value choices. To "win" all they had to do is answer the questions with the most reasonable response (not all questions had a strictly right or wrong answer).

The students were also informed that there were 25 possible points and different values for each question would be awarded based on their responses. The game structure allowed multiple attempts to answer each question and unlimited attempts to re-play the game to get the maximum points; prior to playing the game students were informed that they could re-play to get maximum points but were not told how many attempts were allowed per question. The main purpose of including multiple attempts and scored questions was to provide an immediate feedback mechanism that the students could use to track their progress, better understand their decisionmaking process in the context of the given questions, and keep the students engaged and motivated by not having to "start over" at every incorrect answer. 


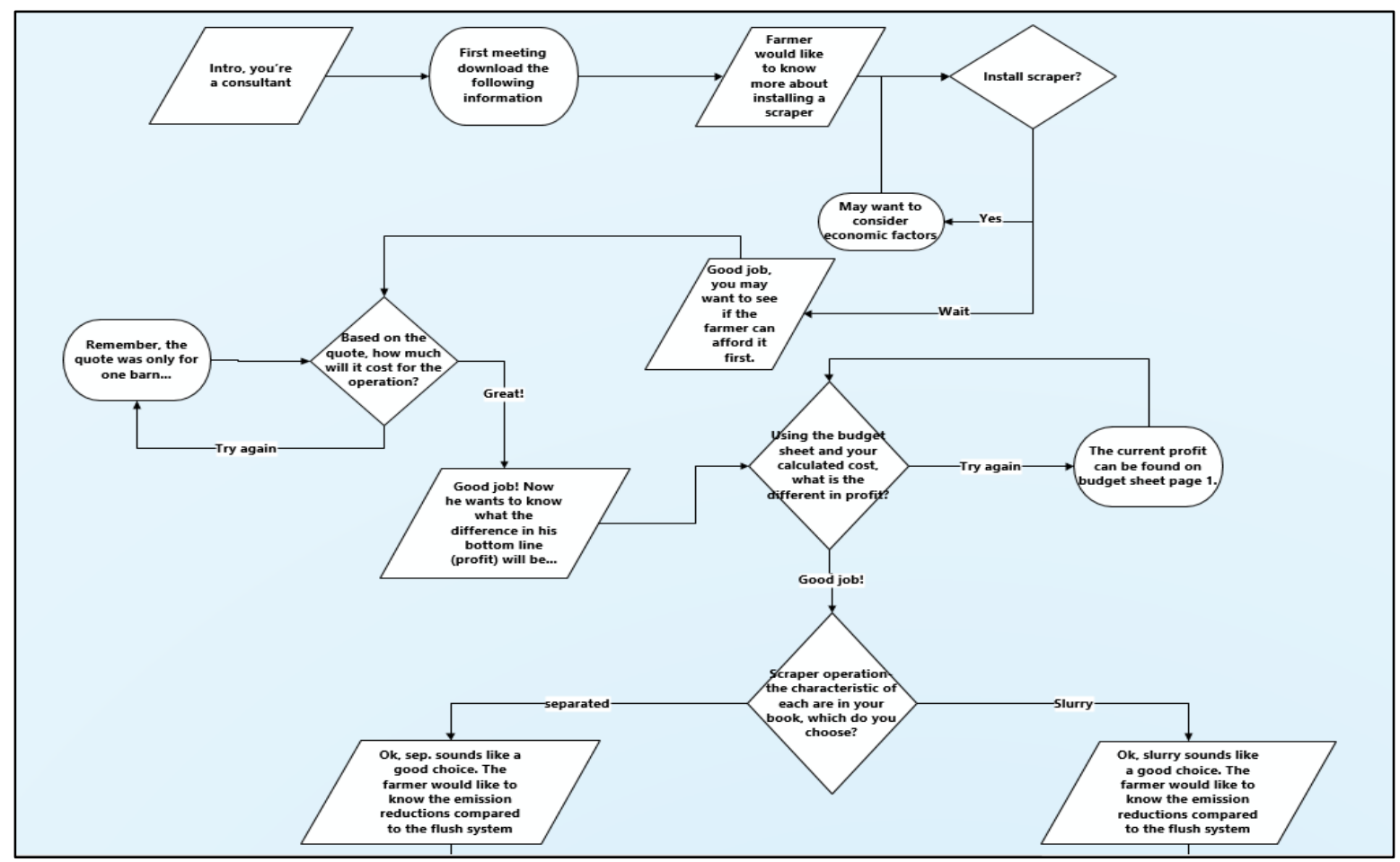

Fig. 3: Partial view of decision tree for game

\section{Game Play}

On the introductory screen (Fig. 4) the students were informed they would play the role of a consultant who has been hired by a farmer to assist him in making some important decisions regarding implementing new technologies for waste and nutrient management. The technologies considered were a flush system versus a scraper system (which could be operated to collect whole slurry or separate liquids and solids) for waste collection, an existing lagoon for waste storage, a covered lagoon for waste treatment and an ammonia stripping column for nitrogen recovery. In addition to building upon their previous course knowledge (waste treatment, nutrient management, economic and environmental modeling, and technologies for resource recovery) the students were provided with a technical report which contained site-specific farm data including soil maps/plots, a nutrient management plan, waste characteristics for different scenarios, and budget sheets. It was important that all information necessary to complete the game was either provided in

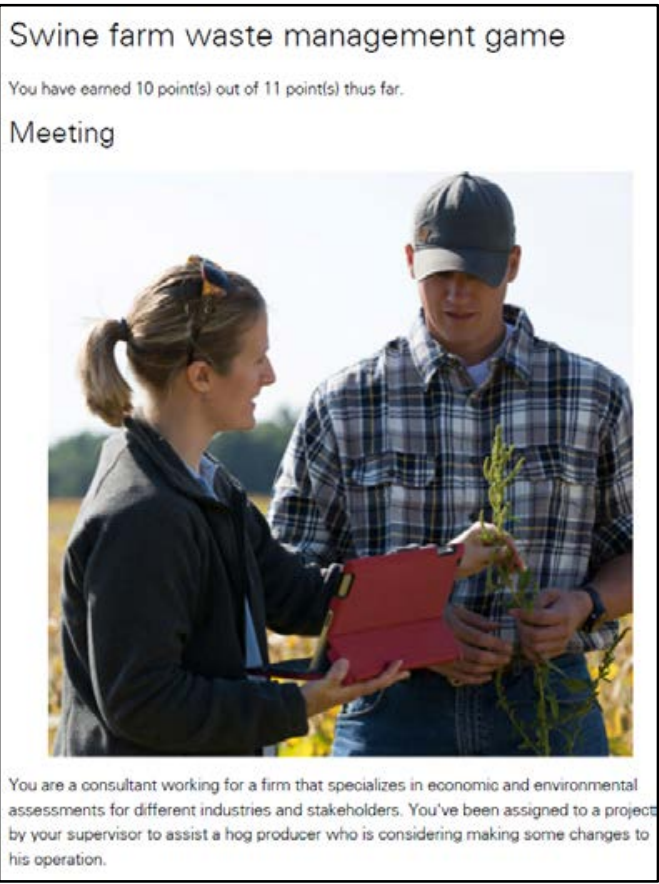

Fig. 4: Swine farm game the technical report or based on students' knowledge from previous course topics. 


\section{Assessment}

The students were assessed using graded and non-graded activities; the graded methods implemented environmental and economic modeling quizzes while the non-graded methods implemented pre and post surveys and completion of the game module. Attempts for each game scenario were not individually recorded, however, based on Moodle statistics for the activity among those students who participated, four students attempted the game more than once, two students completed the game on the first try with a score of $100 \%$, and the average overall score for game play was $80 \%$. Game completion times ranged from approximately 13 minutes to 47 minutes.

\section{Surveys}

Pre and post surveys were used to qualitatively identify 1) Students' self-identified understanding of the main concepts prior to and after completing the module and 2) How effective the students thought various tools implemented throughout the module were in helping them to reinforce the previously learned concept. A combination of question types was used in the pre and post surveys including Likert scale, multiple choice, and open-ended. The pre survey was divided into two parts; the first part (Pre knowledge survey part 1) used a Likert scale to gauge how familiar the students were with specific terms or concepts. The second part of the presurvey (Pre knowledge survey part 2) involved multiple choice questions and asked the students to identify the source(s) of information related to their familiarity with the terms and concepts presented in part 1 The post survey was separated into three parts; the first part was identical to the pre survey (Post knowledge survey part 1). The second (Post knowledge survey part 2) asked the students to identify, using a Likert scale, how well specific Moodle activities and additional resources helped them to better understand the concepts and topics presented. The third (Post knowledge survey part 3) also asked the students, using a Likert scale, to identify how helpful the simulation (decision-making) game was in reinforcing specific concepts and topics but also included an open-ended question in which the students could provide any additional comments or feedback that would help enhance learning and teaching the topics and concepts presented (See Appendix A for all pre and post survey questions).

\section{Quizzes}

Two graded quizzes were implemented in the first part of the module which the students had the option of completing at any point during the two week time period. The quizzes (see Appendix B for all quiz questions) were based on module part 1 topics, environmental assessment and economic assessment. For the environmental assessment quiz, the students were informed prior to attempting the quiz that it was based on LCA concepts. Students were allowed three attempts, received immediate feedback (hints to guide them toward relevant content), and received a final grade based on the highest grade. The quiz included a mix of $\mathrm{T} / \mathrm{F}$, multiple choice, and drag and drop questions. The economic quiz was described before the attempt as general information and also included a mix of T/F, multiple choice, and drag and drop questions. Students were allowed 3 attempts and received a final grade based on the highest graded attempt but were not given hints. All questions were taken directly from the Moodle book pages and at the end of both quizzes students had access to see the correct answers. 


\section{Results and discussion}

Results for each question of part 1 of the pre and post knowledge surveys are shown in Fig 5. In the pre survey $(n=14)$ on average $43.5 \%$ of students had never heard of or were not very familiar with the terminology and concepts prior to completing the module; while $56.4 \%$ were somewhat or very familiar. In the post survey $(n=10)$ on average $11.0 \%$ of students indicated they had never heard of this or were not very familiar with the terminology and concepts after completing the module and $89.0 \%$ were somewhat or very familiar overall terminology and concepts. With the exception of Q5 and Q6 in which students indicated they were relatively familiar with the terms prior to completing the module, on a per-question, student responses indicated a trend of

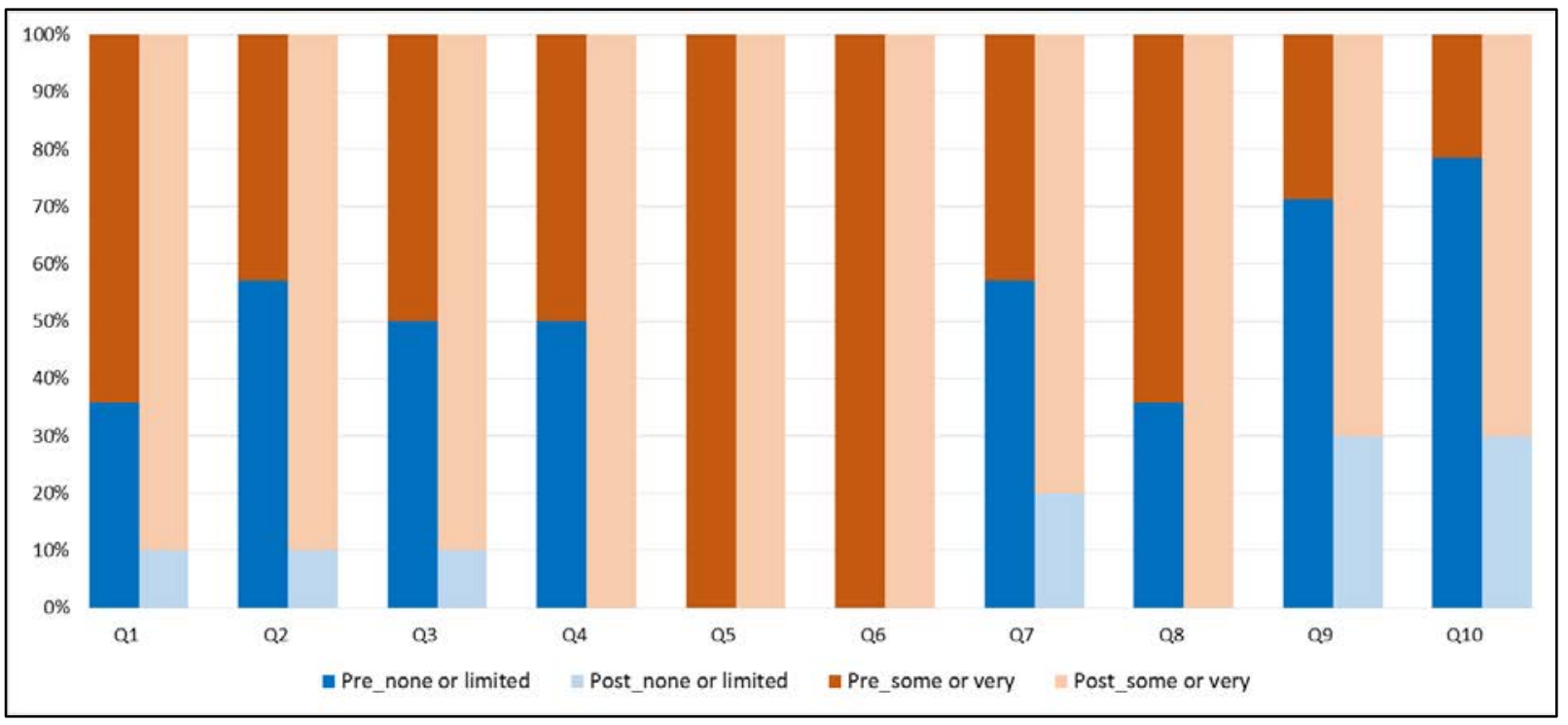

Fig. 5: Pre and post knowledge survey part 1 (Questions in Appendix A)

increased knowledge of terminology and concepts post module completion when compared to pre completion of the module. For the pre knowledge survey part 2 (Fig. 9 in Appendix C), the majority of students who were somewhat or very familiar with the terms and concepts indicated their sources were from their place of employment or another academic institution. Results for post survey part 2 student feedback on Moodle activities and resources and post survey part 3 student feedback on the decision-making game are shown in Fig. 10 and Fig. 11 of Appendix C. Student feedback on Moodle activities and resources indicates that the majority of students found the book text, presentations, glossary, and simulation game to be somewhat helpful in conveying the information presented. However, the same figure illustrates that guided examples, videos, and quizzes were more helpful overall. Student feedback from the decision-making game indicate that all students felt the game was either somewhat or very helpful. Average overall quiz grades for the environmental quiz $(n=10)$ and economic quizzes $(n=10)$ were $90.71 \%$ and 83.33\% respectively, the distribution of points and frequency of students' grades are in shown in Fig. 12 and Fig. 13 in Appendix C.

\section{Limitations and Future work}


On their own, the Moodle book and lesson activities are relatively static tools. However, they can be enhanced by incorporating links, videos, and pictures, branching, etc. to make them more user-friendly and interactive. Based on the intended outcome(s), other platforms and resources may be better suited to accommodate integrated learning in other situations. While the quizzes were graded and mandatory the surveys were not which resulted in variable participation both between surveys (pre and post) and within survey questions (not all that participated answered all questions). In addition, the surveys were implemented anonymously which meant that there was no way to comparatively assess on an individual basis which students had increased understanding of the terminology and concepts. The original application of this module was carried out in a distance learning environment however the content could certainly be presented in a traditional or flipped classroom scenario. For example, students could complete part one of the module (book text, quizzes, videos) independently online while presentations are given in person and the decision-making game is completed on either an individual basis or in groups (as teams). In reality most classes (content-wise) are blended in nature in some way; and regardless of the presented method, the decision-making game provides an integrated component and level of attainment that students would not have otherwise. In essence, it is including versus excluding the game, rather than presenting it online versus in person that is key. As with any DL or traditional course the proof is in the planning. Even though much of the background information and data were compiled prior to planning and implementing the module, it still took nearly a semester to create, refine, and execute the final product. The initial application of the module was a novel addition to an existing course and served as a basis for future development but currently there is no way to compare the development of this module to a traditional or flipped class in terms of time, structure, or efficacy. Due to time constraints additional game and gamification elements were not included in the first version of the module. It is anticipated that a second generation of the module will include more advanced gamification elements (i.e. points, badges), expanded content to accommodate a full semester course, and in time could produce a generic and adaptable stand-alone tool used for information transfer applied to variable topic areas and stakeholders.

\section{Acknowledgements}

We would like to thank the Distance Education and Learning Technology Applications center (DELTA) at North Carolina State University for their assistance in recording and editing the presentations and Murphy Brown, LLC whose funding provided the background for economic and environmental assessment research used in the module.

\section{References}

[1] "Best practices in online teaching strategies," Hanover Research Council, 2009.

[2] “Gamification”, in: Merriam-Webster, [online], (n.d.). Available: http://MerriamWebster.com [Accessed Jan 1, 2018].

[3] Brian Burke, "Gartner Redefines Gamification," 2014, [online]. Available: https://blogs.gartner.com/brian_burke/2014/04/04/gartner-redefines-gamification/

[4] A. Del Blanco, J. Torrente, P. Moreno-Ger, B. Fernández-Manjón, "Integrating adaptive games in student-centered virtual learning environments," International Journal of Distance Education Technologies (IJDET), vol. 8, (3), pp. 1-15, 2010. 
[5] H. L. M. C. Bell-Huff, "Using simulation experiences, real customers, and outcome driven innovation to foster empathy and an entrepreneurial mindset in a sophomore engineering design studio," paper presented at the 2017 ASEE Annual Conference \& Exposition, Columbus, Ohio, 2017.

[6] A. Salado, J. R Morelock, A. Baghaei Lakeh, "Decision-making, information seeking, and compromise: A simulation game activity in global industrial management”, paper presented at the 2017 ASEE Annual Conference \& Exposition, Columbus, Ohio, 2017.

[7] Z. Mahmud, P. J. Weber, J.P. Moening, "Gamification of engineering courses," paper presented at the 2017 ASEE Annual Conference \& Exposition, Columbus, Ohio, 2017.

[8] O. Pedreira, F. García, N. Brisaboa, M. Piattini, "Gamification in software engineering-A systematic mapping," Information and Software Technology, vol. 57, pp. 157-168, 2015.

[9] D. R. Krathwohl, “A revision of Bloom's taxonomy: An overview,” Theory into practice, vol. 41, (4), pp. 212-218, 2002. 


\section{Appendix A}

\begin{tabular}{|c|c|c|c|c|}
\hline $\begin{array}{l}\text { Please indicate how familiar you are with the } \\
\text { following terms or concepts? }\end{array}$ & $\begin{array}{l}\text { Have never } \\
\text { heard of this }\end{array}$ & $\begin{array}{l}\text { Not very } \\
\text { familiar }\end{array}$ & $\begin{array}{l}\text { Somewhat } \\
\text { familiar }\end{array}$ & $\begin{array}{l}\text { Very } \\
\text { Familiar }\end{array}$ \\
\hline 1. Environmental life cycle assessment * & 0 & 0 & 0 & 0 \\
\hline 2. Decision support tools * & 0 & 0 & 0 & 0 \\
\hline 3. Gasification* & 0 & 0 & 0 & 0 \\
\hline 4. Economic input output analysis * & 0 & 0 & 0 & 0 \\
\hline 5. Anaerobic digestion * & 0 & 0 & 0 & 0 \\
\hline 6. Sustainability * & 0 & 0 & 0 & 0 \\
\hline 7. Life cycle costing * & 0 & 0 & 0 & 0 \\
\hline 8. Solids separation * & 0 & 0 & 0 & 0 \\
\hline 9. Mass transfer operation: air stripping * & 0 & 0 & 0 & 0 \\
\hline 10. Mass transfer operation: air scrubbing * & 0 & 0 & 0 & 0 \\
\hline
\end{tabular}

Fig. 6: Pre and post knowledge survey part 1 questions

\begin{tabular}{|c|c|c|c|c|c|c|}
\hline $\begin{array}{l}\text { For any of the terms or concepts in question one } \\
\text { that you identified as somewhat or very familiar } \\
\text { please indicate below your source(s). Select all } \\
\text { that apply. }\end{array}$ & $\begin{array}{l}\text { NCSU } \\
\text { course }\end{array}$ & $\begin{array}{l}\text { Another } \\
\text { academic } \\
\text { institution }\end{array}$ & $\begin{array}{c}\text { News } \\
\text { or } \\
\text { media }\end{array}$ & $\begin{array}{c}\text { Place of } \\
\text { employment }\end{array}$ & other & N/A \\
\hline 11. Environmental life cycle assessment & $\square$ & $\square$ & $\square$ & $\square$ & $\square$ & $\square$ \\
\hline 12. Decision support tools & $\square$ & $\square$ & $\square$ & $\square$ & $\square$ & $\square$ \\
\hline 13. Gasification & $\square$ & $\square$ & $\square$ & $\square$ & $\square$ & $\square$ \\
\hline 14. Economic input output analysis & $\square$ & $\square$ & $\square$ & $\square$ & $\square$ & $\square$ \\
\hline 15. Anaerobic digestion & $\square$ & $\square$ & $\square$ & $\square$ & $\square$ & $\square$ \\
\hline 16. Sustainability & $\square$ & $\square$ & $\square$ & $\square$ & $\square$ & $\square$ \\
\hline 17. Life cycle costing & $\square$ & $\square$ & $\square$ & $\square$ & $\square$ & $\square$ \\
\hline 18. Solids separation & $\square$ & $\square$ & $\square$ & $\square$ & $\square$ & $\square$ \\
\hline 19. Mass transfer operation: air stripping & $\square$ & $\square$ & $\square$ & $\square$ & $\square$ & $\square$ \\
\hline 20. Mass transfer operation: air scrubbing & $\square$ & $\square$ & $\square$ & $\square$ & $\square$ & $\square$ \\
\hline
\end{tabular}

Fig. 7: Pre knowledge survey part 2 questions 


\begin{tabular}{|l|c|c|c|c|}
\hline $\begin{array}{l}\text { How well do you feel the following activities or } \\
\text { resources helped you to better understand the concepts } \\
\text { and topics presented? }\end{array}$ & $\begin{array}{c}\text { Not at } \\
\text { all } \\
\text { helpful }\end{array}$ & $\begin{array}{c}\text { Not } \\
\text { very } \\
\text { helpful }\end{array}$ & $\begin{array}{c}\text { Somewhat } \\
\text { helpful }\end{array}$ & $\begin{array}{c}\text { Very } \\
\text { helpful }\end{array}$ \\
\hline 11. Book chapter text* & & & \\
\hline 12. Videos* & & & & \\
\hline 13. PowerPoint presentations* & & & & \\
\hline 14. Glossary* & & & & \\
\hline 15. References* & & & & \\
\hline 16. Quizzes* & & & & \\
\hline 17. Guided examples* & & & & \\
\hline 18. Simulation game* & & & & \\
\hline
\end{tabular}

\begin{tabular}{|l|c|c|c|c|}
\hline $\begin{array}{l}\text { How helpful do you feel the simulation game was in } \\
\text { reinforcing the following concepts and topics? }\end{array}$ & $\begin{array}{c}\text { Not at } \\
\text { all } \\
\text { helpful }\end{array}$ & $\begin{array}{c}\text { Not } \\
\text { very } \\
\text { helpful }\end{array}$ & $\begin{array}{c}\text { Somewhat } \\
\text { helpful }\end{array}$ & $\begin{array}{c}\text { Very } \\
\text { helpful }\end{array}$ \\
\hline 19. Whole farm waste management * & & & & \\
\hline 20. Waste treatment technologies* & & & & \\
\hline 21. Nutrient recovery* & & & & \\
\hline 22. Environmental impact* & & & & \\
\hline 23. Economic modeling* & & & & \\
\hline 24. Environmental modeling* & & & \\
\hline 25. Integrated assessment* & & & & \\
\hline 26. Sustainability * & & & & \\
\hline
\end{tabular}

27. Please provide any additional comments or feedback that you believe would help enhance learning and teaching these types of concepts.

Fig. 8: Post knowledge survey part 2 \& 3 questions 


\section{Appendix B}

\section{Environmental Assessment Quiz}

1. Based on ISO standards the goal of a study should include which of the following? (select all that apply)
a. Impact assessment methods
b. Allocation methods
c. Data requirements and assumptions
d. Intended application
e. Reason for carrying out the study
f. Intended audience
g. System boundary

2. You work for a consulting firm that has been retained to conduct a preliminary LCA for a swine finishing operation in Southeastern NC. The farm currently uses a flush system for waste removal, a lagoon for storage and treatment, and land applies lagoon effluent to corn and soybeans using irrigation. They would like to compare their current system to one that utilizes the following alternative technologies - a mechanical scraper for waste removal, an above ground digester for treatment, and the existing lagoon for digestate storage. Biogas produced from the digester will be used to offset on-farm electricity.

Based on the above problem statement, the main function of the system is to
a. Grow corn and soybeans
b. Produce swine
c. Produce renewable energy
d. Determine which storage and treatment technology is best
e. Manage and treat waste

3. You work for a consulting firm that has been retained to conduct a preliminary LCA for a swine finishing operation in Southeastern NC. The farm currently uses a flush system for waste removal, a lagoon for storage and treatment, and land applies lagoon effluent to corn and soybeans using irrigation. They would like to compare their current system to one that uses alternative technologies including a mechanical scraper for waste removal, an above ground digester for treatment, and the existing lagoon for digestate storage. Biogas produced from the digester will be used to offset on-farm electricity.

Based on the above problem statement, the most appropriate function unit is
a. $1 \mathrm{kWh}$ of electricity
b. 1 year of animal production
c. 1 ton of treated waste
d. $1 \mathrm{~kg}$ of pork
e. 1 ton of raw waste 
4. An LCA process generates two co-products, renewable energy, and organic fertilizer that are considered alternatives to marginal products currently available on the market. The best way to model the avoided environmental impact from using the co-products would be to use
a. system expansion
b. economic allocation
c. physical allocation
d. partitioning

5. The Global Warming Potential (GWP) of the nitrous oxide, carbon dioxide, and methane are , and respectively.

Select one:
a. $25,1,250$
b. $1,25,250$
c. $1,250,25$
d. $25,250,1$
e. $250,1,25$
f. $250,25,1$

6. Regarding the main stages of LCA, drag and click the following terms to their appropriate areas.

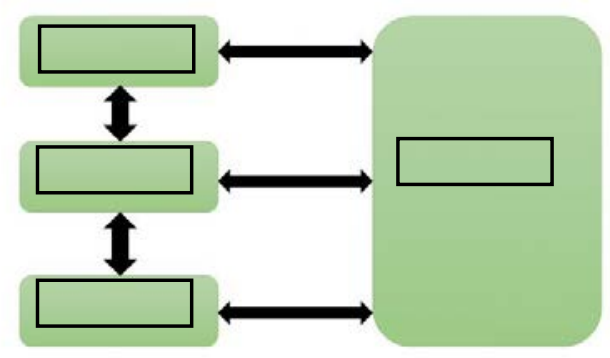

Interpretation, Impact assessment, Inventory analysis, Goal and scope definition

7. Regarding the main processes, inputs, and outputs in a product's life cycle, drag and click the following terms to their appropriate areas.

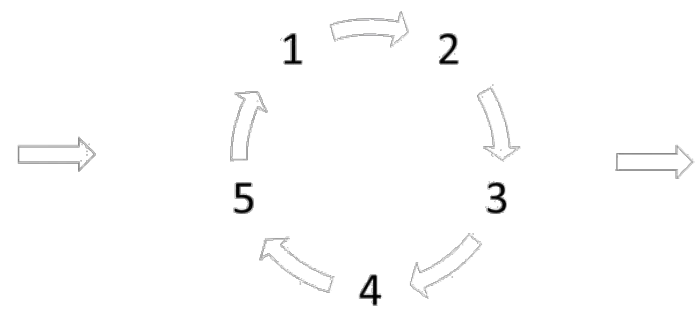

Transportation, Material extraction, Use, Materials and energy, End of Life, Emissions and waste, Manufacturing 
8. Characterization is best defined as...

Select one:

a. The process of converting indicator results of different impact categories by using numerical factors based on value-choices.

b. The process of multiplying all substances by a factor which reflects their relative contribution to the environmental impact, quantifying how much impact a product or service has in each impact category.

c. The process of showing the relative significance of the calculated impact category result to the overall environmental problem of that impact category

d. The process of sorting pollutants according to the effects they have on the environment.

9. Normalization is best defined as...

Select one:

a. The process of sorting pollutants according to the effects they have on the environment.

b. The process of converting indicator results of different impact categories by using numerical factors based on value-choices.

c. The process of multiplying all substances by a factor which reflects their relative contribution to the environmental impact, quantifying how much impact a product or service hasin each impact category.

d. The process of showing the relative significance of the calculated impact category result to the overall environmental problem of that impact category

10. Classification is best defined as...

Select one:

a. The process of converting indicator results of different impact categories by using numerical factors based on value-choices.

b. The process of sorting pollutants according to the effects they have on the environment.

c. The process of multiplying all substances by a factor which reflects their relative contribution to the environmental impact, quantifying how much impact a product or service hasin each impact category.

d. The process of showing the relative significance of the calculated impact category result to the overall environmental problem of that impact category

\section{Economic assessment quiz}

1. __ is a concept based on general equilibrium theory developed by Nobel Prizewinning economist Wassily Leontief.
a. Partial budgeting
b. Bioeconomics
c. Life cycle costing
d. Input-output analysis 
2. of the following areas.

is based on the principle that business changes have effects in one or more

- Increase in income

- Reduction or elimination of costs

- Increase in costs

- Reduction or elimination of income

a. Bioeconomics

b. Input-output analysis

c. Partial budgeting

d. Life cycle costing

3. Suppose a hog farmer has a traditional lagoon sprayfield system and is considering installing a new technology that would initially (in the short run) increase costs and reduce income but could over time (in the long run) likely increase income at a reduced cost. To evaluate the difference in current farm income and costs versus future farm income and costs from installing the technology, the farmer would most likely need to use
a. Input-output analysis
b. Partial budgeting
c. Life cycle costing
d. Bioeconomics

4. generally requires large amounts of data and is limited to modeling a single product or process over its lifetime but it is still a powerful economic optimization tool for capturing both upstream and downstream flows throughout an entire supply chain.
a. Bioeconomics
b. Life cycle costing
c. Partial budgeting
d. Input-output analysis

5. Which of the following statements regarding life cycle costing is correct?

1. Product life cycle costing can promote short-term rewarding in contrast to long-term profitability rewarding.

2. Life cycle costing involves identifying the costs incurred during the different stages of a product's life cycle provides an insight into understanding and managing the total costs incurred throughout its life cycle.
a. The second statement is correct
b. Neither statement is correct
c. The first statement is correct
d. Both statements are correct 
6. The aim of bioeconomic modeling is to understand the interactions and tradeoffs between human systems and environmental systems.

True

False

7. This figure is associated with what economic modeling method?

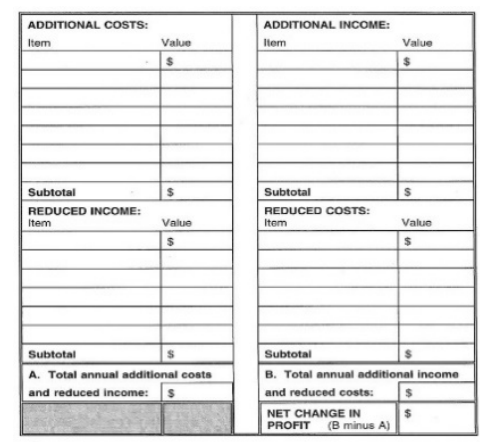
a. Input-output analysis
b. Bioeconomics
c. Partial budgeting
d. Life cycle costing

8. involves using a table or matrix that includes a series of rows and columns of data that quantify the supply chain for sectors of the economy. Industries are listed in the headers of each row and each column and the data in each column corresponds to the level of inputs used in that industry's production function.
a. Life cycle costing
b. Bioeconomics
c. Partial budgeting
d. Input-output analysis

9. The following image describes a simplified structure for what type of economic model?

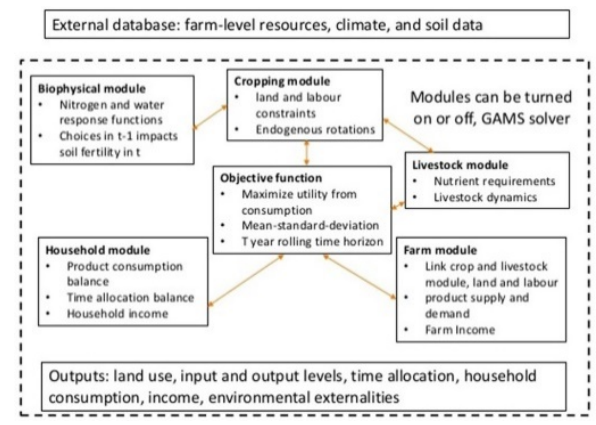
a. Partial budgeting
b. Bioeconomics
c. Input-output analysis
d. Life cycle costing 
10. Which of the following are associated with EIO-LCA? (Select all that apply)
a. Allows for system-level comparisons
b. Results are comprehensive
c. Must link monetary values with physical units
d. Identifies areas for process improvements, weak point analysis
e. Setting system boundary is subjective
f. Allows for specific product comparisons 


\section{Appendix C}

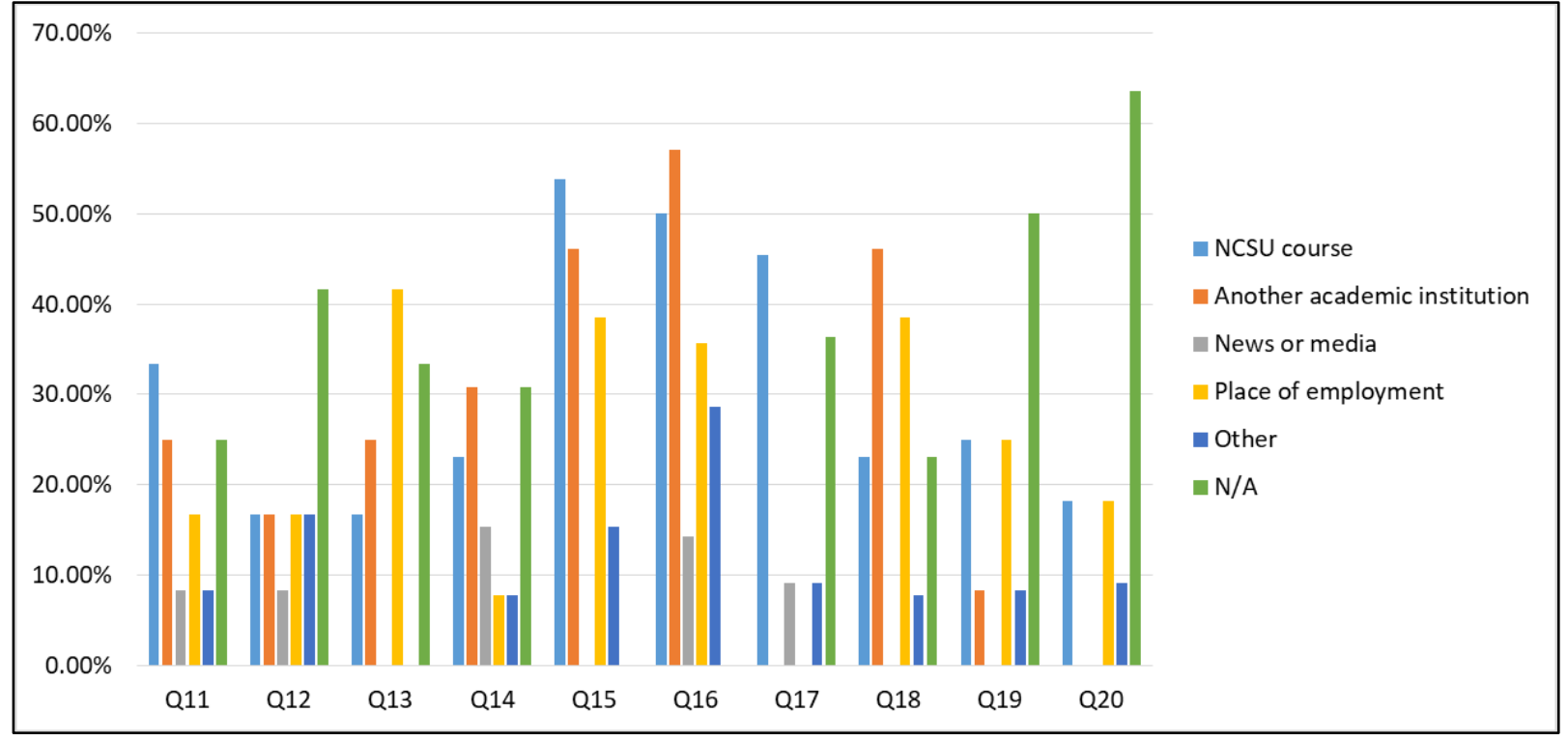

Fig. 9: Pre knowledge survey part 2

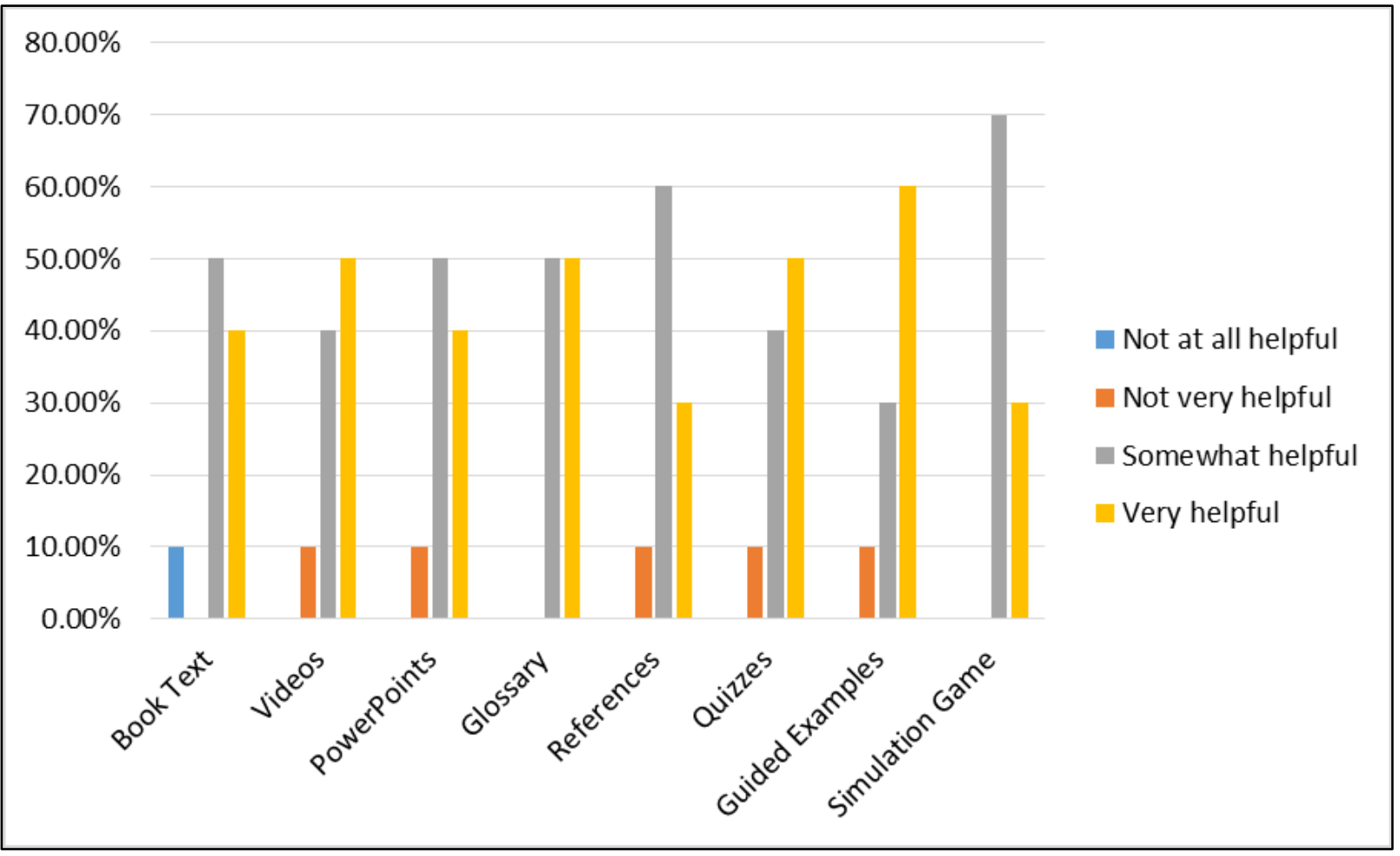

Fig. 10: Post knowledge survey part 2 


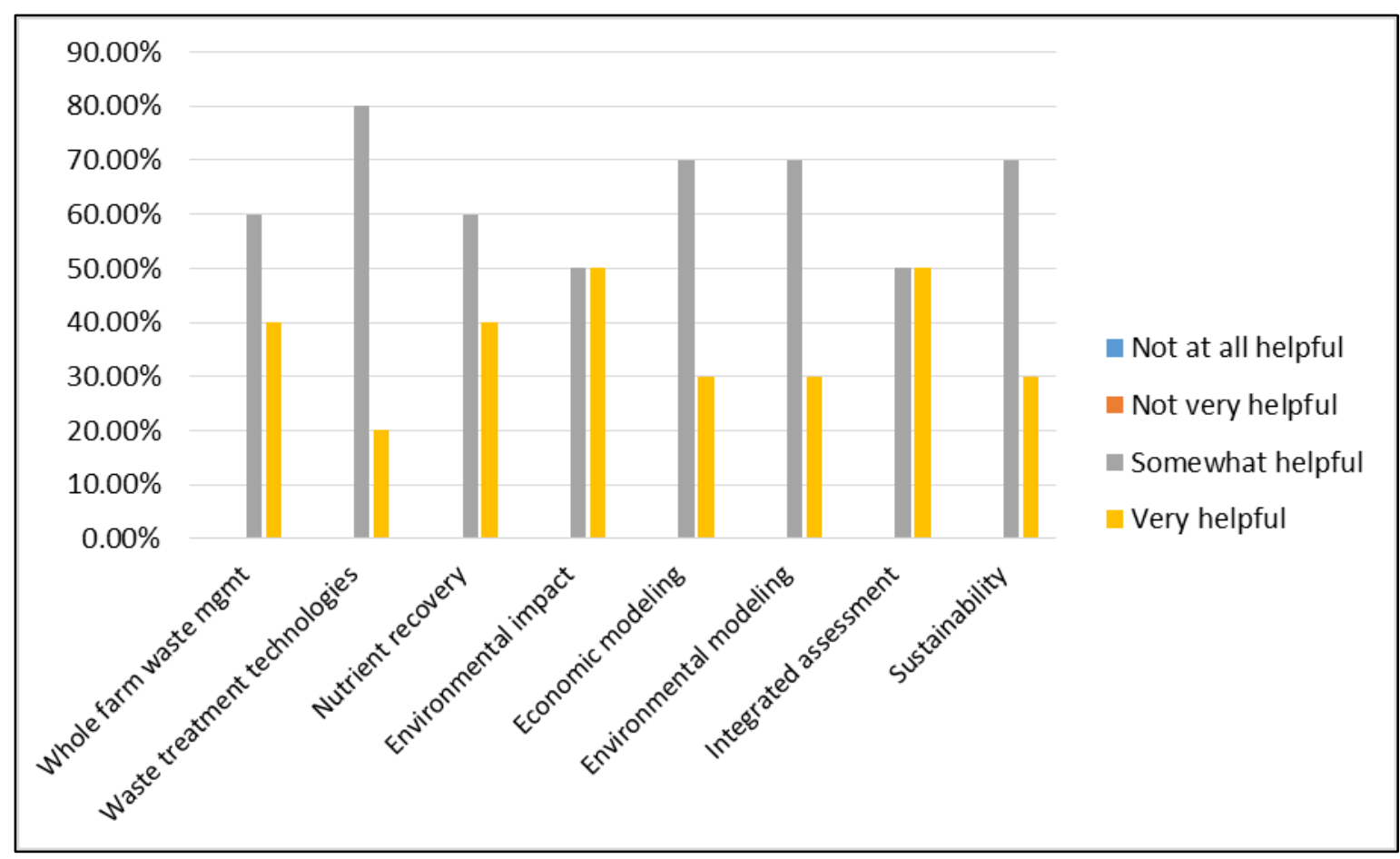

Fig. 11: Post knowledge survey part 3

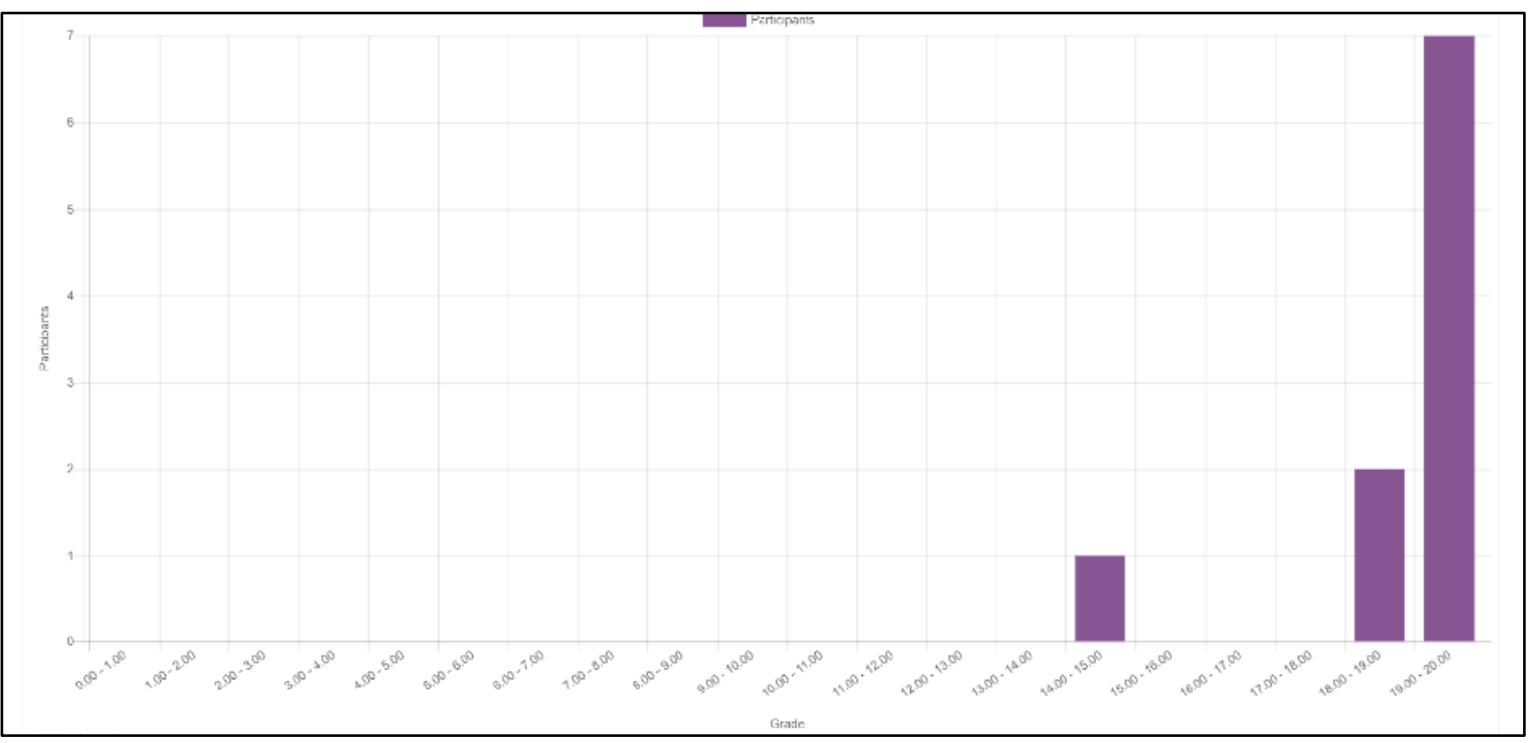

Fig. 12: Student grade distribution for environmental quiz 


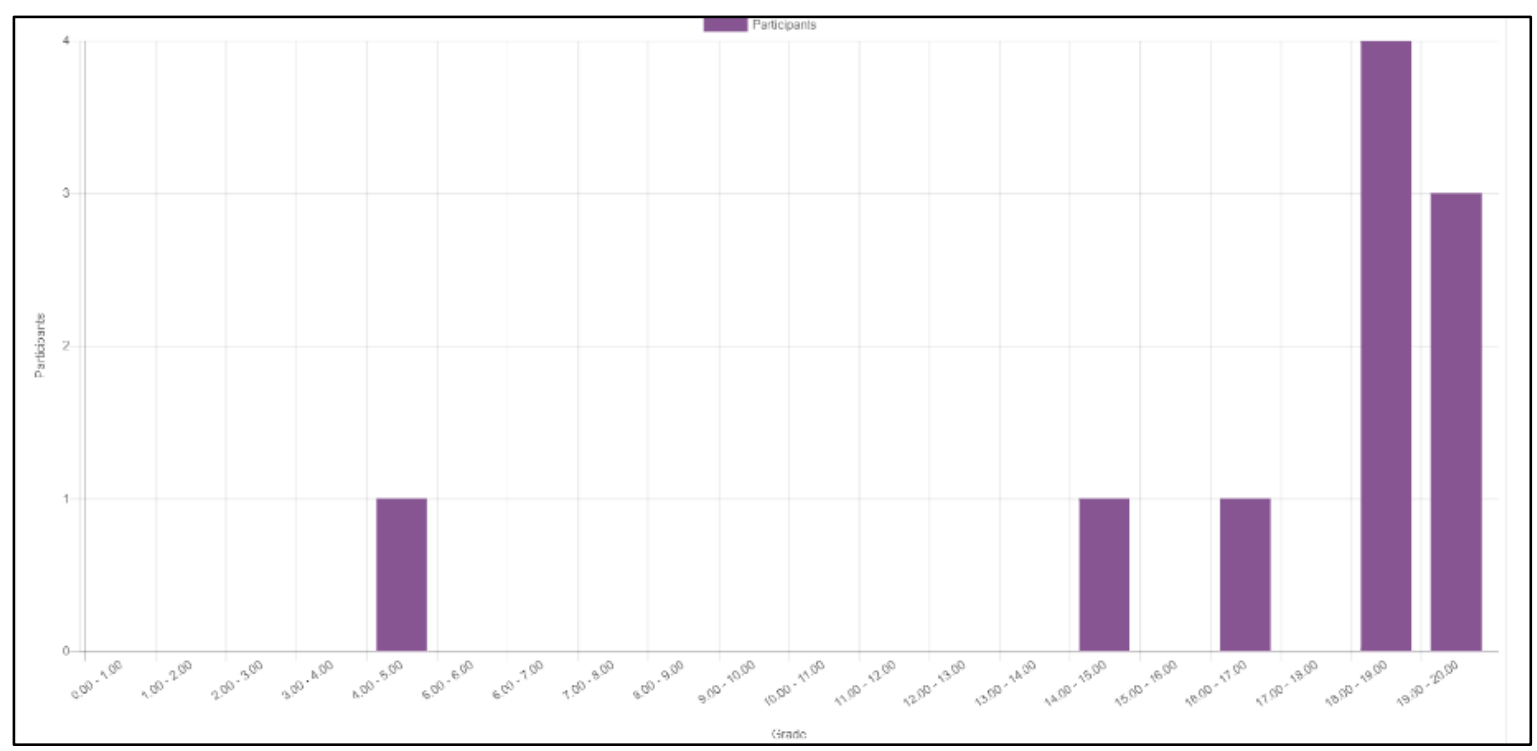

Fig. 13: Student grade distribution for economic quiz 